\title{
Effects of Pitavastatin (LIVALO Tablet) on High Density Lipoprotein Cholesterol (HDL-C) in Hypercholesterolemia - Sub-Analysis of LIVALO Effectiveness and Safety (LIVES) Study
}

\author{
Tamio Teramoto ${ }^{1}$, Hitoshi Shimano ${ }^{2}$, Koutaro Yokote ${ }^{3}$, and Mitsuyoshi Urashima ${ }^{4}$ \\ ${ }^{1}$ Department of Internal Medicine, Teikyo University School of Medicine, Tokyo, Japan \\ ${ }^{2}$ Department of Internal Medicine (Metabolism and Endocrinology), Graduate School of Comprehensive Human Sciences, \\ University of Tsukuba, Ibaraki, Japan \\ ${ }^{3}$ Department of Clinical Cell Biology and Medicine, Chiba University Graduate School of Medicine, Chiba, Japan \\ ${ }^{4}$ Division of Clinical Research and Development, Jikei University School of Medicine, Tokyo, Japan
}

Background: Low high-density lipoprotein cholesterol (HDL-C) is an important clinical risk factor for cardiovascular disease (CVD). Statins have been known to have a potent HDL-C-elevating effect in addition to low-density lipoprotein cholesterol (LDL-C)-lowering effects.

Methods: The database of LIVALO effectiveness and safety (LIVES) Study, a large-scale $(n=20,279)$, long-term (104 weeks), prospective post-marketing surveillance of hypercholesterolemic patients treated with pitavastatin, was used to evaluate and analyze effects on plasma lipids, especially focusing on HDL-C.

Results: Total cholesterol (TC) $(-21.0 \%)$ and LDL-C (-31.3\%) were significantly reduced. The decrease in triglyceride (TG) was significant in hypertriglyceridemic patients. HDL-C was elevated by $5.9 \%$ and $24.6 \%$ in all and in patients with low HDL-C levels (less than $40 \mathrm{mg} / \mathrm{dL}$ ) at baseline, respectively $(p<0.0001)$. In time-course analysis, elevation of HDL-C in the low HDL-C group was enhanced by $14.0 \%$ and $24.9 \%$ at 12 weeks and 104 weeks, respectively. A significant increase in HDL-C by pitavastatin treatment was also observed after switching from other statins. Multivariable analysis showed that BMI, diabetes, liver disease, and pre-treated other cholesterol-lowering drugs emerged as significant factors influencing HDL-C.

Conclusions: Pitavastatin had stable clinical effects on LDL-C, TG, and HDL-C for 104 weeks. It was noteworthy that HDL-C in patients with low HDL-C was continuously increased by this agent during the period tested.

J Atheroscler Thromb, 2009; 16:654-661.

Key words; Statin, HMG-CoA reductase inhibitor, Low-density cholesterol, Cardiovascular disease

\section{Introduction}

Serum high-density lipoprotein cholesterol (HDL-C) is known to be a protective marker for cardiovascular disease (CVD). In the Framingham study, lower HDL-C levels were indicated as a higher risk of

Address for correspondence: Tamio Teramoto, Department of Internal Medicine, Teikyo University School of Medicine, 2-11-1, Kaga, Itabashi, Tokyo, Japan

E-mail: ttera@med.teikyo-u.ac.jp

Received: February 9, 2009

Accepted for publication: April 16, 2009
$\mathrm{CVD}^{1)}$. In the PROCAM study, univariate analysis revealed a significant association between the incidences of atherosclerotic cardiac heart disease and HDL-C levels ${ }^{2)}$. According to the analysis of NIPPON DATA90, a cohort study of Japanese residents, serum HDL-C levels were inversely associated with all-cause mortality in the Japanese population ${ }^{3)}$. In the Japan Lipid Intervention Trial (J-LIT) study, a 6 year cohort study of Japanese hypercholesterolemic patients, it was shown that HDL-C was inversely correlated with the risk of coronary events ${ }^{4)}$. Thus, raising HDL-C is considered to reduce the risk of CVD. 
Some clinical trials have reported that statins increased HDL-C levels by $5-15 \%{ }^{5-8}$; however, the long-term effects of statins on HDL-C have not been studied well in Japanese patients.

Pitavastatin (LIVALO Tablet $1 \mathrm{mg}$ or $2 \mathrm{mg}$ ) is an HMG-CoA reductase inhibitor, which was reported to reduce low-density cholesterol (LDL-C) and triglyceride (TG) by enhancing LDL receptors and suppressing the secretion of very low-density lipoprotein $(\text { VLDL })^{9)}$ in animal models. Clinical studies conducted prior to its approval in Japan revealed that pitavastatin has efficacy in not only lowering LDL-C, but also lowering TG and raising HDL-C ${ }^{10}$.

The LIVALO effectiveness and safety (LIVES) study was a large-scale, long-term, prospective postmarketing surveillance of pitavastatin, including more than 20,000 hypercholesterolemia patients under ordinary clinical practice ${ }^{11)}$. Using the database of the LIVES study, we analyzed the effects of pitavastatin on HDL-C as well as on LDL-C and TG in patients who were followed, by the end of the study. The clinical factors that might affect HDL-C elevation were also analyzed.

\section{Subjects and Methods}

\section{Survey Participants}

The design and results of the LIVES study were described previously ${ }^{11)}$. Patients with hypercholesterolemia or familial hypercholesterolemia were registered in this study. Patients were enrolled using a central registration system, with each patient enrolled in the study within 14 days after the start of treatment with pitavastatin. Patients were observed during 2 years after the start of treatment until dropout. Of the 20,279 patients recruited, 19,925 patients were analyzed for safety and 18,031 patients were analyzed for the effectiveness of pitavastatin.

In this study, the data of 18,031 patients were analyzed for effectiveness. Since the main objective of the LIVES study was to recognize any unknown adverse reactions and evaluate the incidence and pattern of adverse reactions, not all efficacy data were always available during the whole study period. Thus, from these patients, lipid changes were analyzed in patients whose efficacy data were eligible at 104 weeks.

\section{Lipid Analysis}

Percent change of TC, LDL-C, TG (all and high TG group ( $\geqq 150 \mathrm{mg} / \mathrm{dL}$ ) at baseline), HDL-C (all and low HDL-C group ( $<40 \mathrm{mg} / \mathrm{dL})$ at baseline), non-HDL-C, and LDL-C/HDL-C were calculated. Concentration of LDL-C was estimated using the Frie- dewald formula $(\mathrm{LDL}-\mathrm{C}=\mathrm{TC}-\mathrm{HDL}-\mathrm{C}-\mathrm{TG} \times 0.2)^{12)}$ for patients with TG concentration $<400 \mathrm{mg} / \mathrm{dL}$.

Time course of LDL-C, TG (high TG group), and HDL-C (all patients and low HDL-C group) for 104 weeks was evaluated in patients whose efficacy data were all available at $0,12,28,52$, and 104 weeks. The increasing trend of HDL-C was analyzed by the linear regression model.

Percent change of HDL-C in patients pre-treated other statins and other cholesterol lowering drugs was also evaluated.

\section{Analysis of Clinical Factors Affecting HDL-C}

The effect of clinical factors, patient baseline characters (gender, pre-or post-menopausal, age, BMI, phenotype of dyslipidemia, and smoking), complication (hypertension, diabetes, heart disease, liver disease, and renal disease), other pre-treated cholesterollowering drug, and dose of pitavastatin, on the change of HDL-C was evaluated.

\section{Statistical Analysis}

All data are expressed as the mean \pm standard deviation. Statistical analysis was performed with a one-sample $t$ test or paired $t$ test in appropriate data. Time course of LDL-C, TG and HDL-C was analyzed by one-way ANOVA for the study period. In factorial analysis, the percent change of HDL-C was adjusted by the baseline HDL-C and analyzed by the ANOVA (F-test). Multivariable analysis was applied by the stepwise method to select factors affecting percent change of HDL-C. JMP ver. 5.1.1 was used for statistical analysis with a significant level of $p<0.05$ (twosided).

\section{Results}

\section{Effects on Plasma Lipids Levels}

Of the total 18,031 patients, 4,086 were used to evaluate TC, 1,455 LDL-C, 4,123 TG, and 3,427 HDL-C, respectively, as patients whose data were available at 104 weeks. The number of patients with baseline TG levels of $150 \mathrm{mg} / \mathrm{dL}$ or over was 2,088 (50.6\%), and baseline HDL-C levels of less than $40 \mathrm{mg} / \mathrm{dL}$ was $346(10.1 \%)$. The demographic characteristics of patients in the LIVES study and this sub-analysis are shown in Table 1. The data in this sub-analysis were similar to those of all patients in the LIVES study. Both the average initial daily dose and most frequent daily dose of LIVALO were $1.62 \mathrm{mg} /$ day.

Percent changes of serum lipids at 104 weeks are listed in Table 2. A significant reduction of TC $(-21.0 \%)$ and LDL-C (-31.3\%) was observed at 104 
Table 1. Patient demographic characteristics

\begin{tabular}{|c|c|c|c|}
\hline \multicolumn{2}{|l|}{ Item } & Patients in LIVES Study & Patients in sub-analysis \\
\hline \multicolumn{2}{|l|}{ No. of patients surveyed } & 20,279 & 4,269 \\
\hline \multicolumn{2}{|l|}{ Female } & $13,633(67.2)$ & $2,868(67.2)$ \\
\hline \multicolumn{2}{|l|}{ Age (year) } & $63.3 \pm 11.3$ & $64.2 \pm 10.9$ \\
\hline \multicolumn{2}{|l|}{ BMI $\left(\mathrm{kg} / \mathrm{m}^{2}\right)$} & $24.25 \pm 3.54$ & $24.42 \pm 3.61$ \\
\hline \multirow[t]{2}{*}{ Hyperlipidemia phenotype } & Па & $10,711(52.8)$ & $2,233(52.3)$ \\
\hline & II b & $8,427(41.6)$ & $1,842(43.1)$ \\
\hline \multicolumn{2}{|l|}{ Co-morbid conditions } & $15,510(76.5)$ & $3,516(82.2)$ \\
\hline \multicolumn{2}{|l|}{ Hypertension } & $9,510(46.9)$ & $2,237(52.4)$ \\
\hline \multicolumn{2}{|l|}{ Diabetes } & $5,174(25.5)$ & $1,447(33.9)$ \\
\hline \multicolumn{2}{|l|}{ Heart disease } & $2,947(14.5)$ & $642(15.0)$ \\
\hline \multicolumn{2}{|l|}{ Liver disease } & $1,606(7.9)$ & 367 (8.6) \\
\hline \multicolumn{2}{|l|}{ Renal disease } & $721(3.6)$ & $182(4.3)$ \\
\hline \multicolumn{2}{|l|}{ Smoking } & $2,640(13.0)$ & $505(11.8)$ \\
\hline \multicolumn{2}{|c|}{ Previous hyperlipidemic medication } & 3,837 (18.9) & $940(22.0)$ \\
\hline \multirow[t]{3}{*}{ Initial daily dose } & $1 \mathrm{mg}$ & $8,002(39.5)$ & $1,658(38.8)$ \\
\hline & $2 \mathrm{mg}$ & $12,164(60.0)$ & $2,581(60.5)$ \\
\hline & $4 \mathrm{mg}$ & $74(0.4)$ & $16(0.4)$ \\
\hline \multirow[t]{3}{*}{ Most frequent daily dosage } & $1 \mathrm{mg}$ & $8,124(40.1)$ & $1,681(39.4)$ \\
\hline & $2 \mathrm{mg}$ & $11,844(58.4)$ & $2,506(58.7)$ \\
\hline & $4 \mathrm{mg}$ & $186(0.9)$ & $45(1.1)$ \\
\hline
\end{tabular}

Table 2. Change of lipid value

\begin{tabular}{|c|c|c|c|c|c|}
\hline & No. of patients & Period & $\begin{array}{l}\text { Lipid value }(\mathrm{mg} / \mathrm{dL}) \\
\quad(\text { Mean } \pm \mathrm{SD})\end{array}$ & $\begin{array}{l}\% \text { change from baseline } \\
\qquad(\text { Mean } \pm \text { SD })\end{array}$ & $p$ value \\
\hline TC & 4,084 & $\begin{array}{l}\text { Baseline } \\
104 \text { weeks }\end{array}$ & $\begin{array}{l}254.1 \pm 37.6 \\
197.7 \pm 33.2\end{array}$ & $-21.0 \pm 15.0$ & $<0.0001$ \\
\hline LDL-C $^{*}$ & 1,455 & $\begin{array}{l}\text { Baseline } \\
104 \text { weeks }\end{array}$ & $\begin{array}{l}165.2 \pm 35.5 \\
110.3 \pm 28.0\end{array}$ & $-31.3 \pm 26.0$ & $<0.0001$ \\
\hline $\begin{array}{l}\text { TG } \\
\text { (Baseline value } \geqq 150 \mathrm{mg} / \mathrm{dL} \text { ) }\end{array}$ & 2,088 & $\begin{array}{l}\text { Baseline } \\
104 \text { weeks }\end{array}$ & $\begin{array}{l}254.9 \pm 141.5 \\
179.8 \pm 112.4\end{array}$ & $-24.2 \pm 37.6$ & $<0.0001$ \\
\hline HDL-C & 3,427 & $\begin{array}{l}\text { Baseline } \\
104 \text { weeks }\end{array}$ & $\begin{array}{l}58.8 \pm 17.1 \\
60.8 \pm 15.9\end{array}$ & $5.9 \pm 21.5$ & $<0.0001$ \\
\hline LDL-C ${ }^{*} / \mathrm{HDL}-\mathrm{C}$ & 1,455 & $\begin{array}{l}\text { Baseline } \\
104 \text { weeks }\end{array}$ & $\begin{array}{l}3.0 \pm 1.1 \\
1.9 \pm 0.7\end{array}$ & $-33.8 \pm 72.2$ & $<0.0001$ \\
\hline
\end{tabular}

*LDL-C was estimated by the Friedewald formula.

weeks. Also, non-HDL-C and LDL-C/HDL-C were reduced significantly $(p<0.0001)$ at 104 weeks. The percent reduction of TG was $6.1 \%$ for the entire population but was $24.2 \%$ in the high TG group. The percent increase of HDL-C was 5.9\% $(p<0.0001)$ for the entire population and $24.6 \%(p<0.0001)$ in the low HDL-C group.

The time course of LDL-C, TG (the high TG 


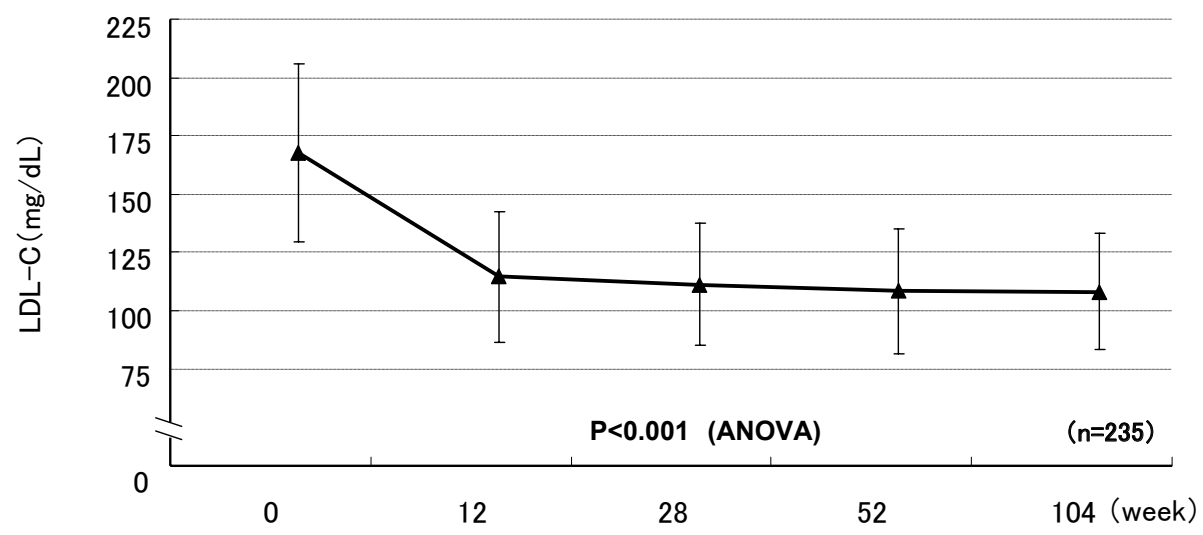

\begin{tabular}{|c|c|c|c|c|c|c|}
\hline \multirow{2}{*}{$(\mathrm{n}=235)$} & $\begin{array}{c}\mathrm{LDL}-\mathrm{C} \\
(\mathrm{mg} / \mathrm{dL})\end{array}$ & $167.7 \pm 38.3$ & $114.2 \pm 28.3$ & $111.1 \pm 26.4$ & $108.2 \pm 27.0$ & $107.8 \pm 25.0$ \\
\cline { 2 - 6 } & $\begin{array}{c}\% \text { change } \\
\text { from baseline }\end{array}$ & 0 & $-32.9 \pm 45.8$ & $-34.0 \pm 39.7$ & $-35.2 \pm 37.0$ & $-36.1 \pm 42.1$ \\
\hline
\end{tabular}

(Mean $\pm S D)$

*LDL-C was estimated by the Friedewald formula.

Fig. 1. Effect of pitavastatin on LDL-C.

Values are the mean $\pm S D$

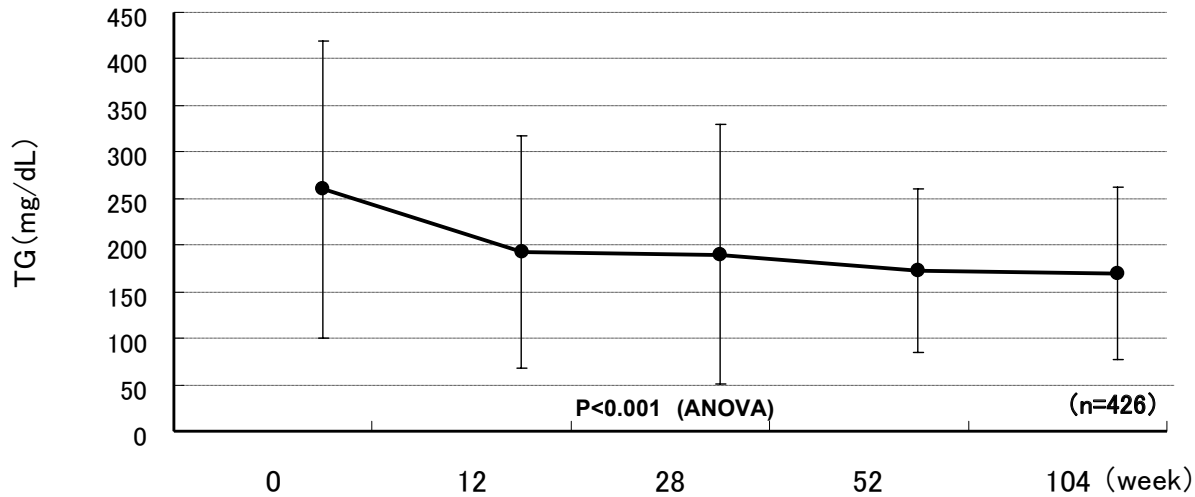

\begin{tabular}{|c|c|c|c|c|c|c|}
\hline \multirow{3}{*}{$(n=426)$} & $\begin{array}{c}\text { TG } \\
(\mathrm{mg} / \mathrm{dL})\end{array}$ & $259.8 \pm 159.9$ & $192.3 \pm 124.6$ & $190.3 \pm 139.1$ & $172.7 \pm 88.3$ & $169.1 \pm 92.3$ \\
\cline { 2 - 7 } & $\begin{array}{c}\% \text { change } \\
\text { from baseline }\end{array}$ & 0 & $-21.7 \pm 32.2$ & $-21.6 \pm 37.9$ & $-27.9 \pm 32.5$ & $-28.3 \pm 37.9$ \\
\hline
\end{tabular}

$($ Mean $\pm S D)$

Fig. 2. Effect of pitavastatin on TG. Baseline TG value is $150 \mathrm{mg} / \mathrm{dL}$ and over.

Values are the mean \pm SD

group), and HDL-C (all patients and the low HDL-C group) for 104 weeks is shown (Fig. 1, 2, 3). Significant reduction of LDL-C was observed at 12 weeks $(-32.9 \%)$. The reduction rate of LDL-C was stable and was $-36.1 \%$ at 104 weeks $(p<0.001$; ANOVA). The reduction rate of TG was $-21.7 \%$ at 12 weeks and a greater reduction rate $(-28.3 \%)$ was observed at 104 weeks $(p<0.001$; ANOVA $)$. In the analysis of all patients, HDL-C was elevated by $2.3 \%$ at 12 weeks, and by $7.5 \%$ at 104 weeks ( $p<0.05$; ANOVA). In the analysis of low HDL-C level patients, HDL-C was elevated by $14.0 \%$ at 12 weeks, and by $24.9 \%$ at 104 weeks $(p<0.001$; ANOVA). The increasing trend of HDL-C was confirmed by the linear regression model $(p<0.001)$.

Percent change of HDL-C in patients pre-treated 


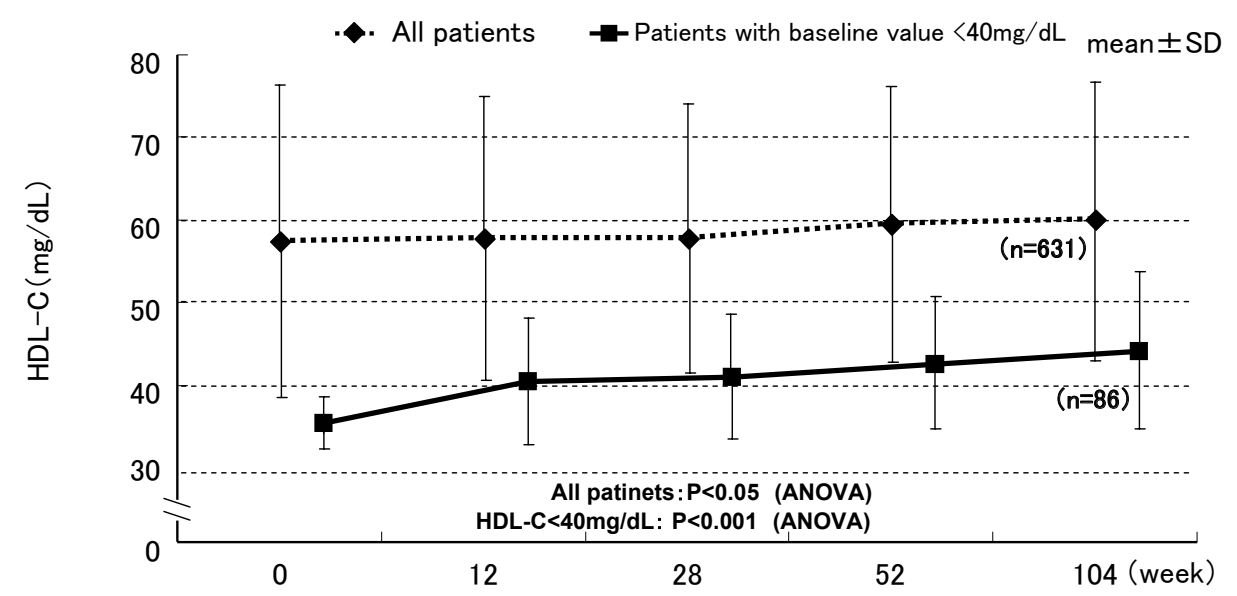

\begin{tabular}{|c|c|c|c|c|c|c|}
\hline \multirow{2}{*}{$\begin{array}{c}\text { All } \\
(\mathrm{n}=631)\end{array}$} & $\begin{array}{c}\mathrm{HDL}-\mathrm{C} \\
(\mathrm{mg} / \mathrm{dL})\end{array}$ & $57.6 \pm 18.8$ & $57.8 \pm 17.0$ & $57.9 \pm 16.2$ & $59.6 \pm 16.5$ & $60.1 \pm 16.6$ \\
\cline { 2 - 7 } & $\begin{array}{c}\% \text { change } \\
\text { from baseline }\end{array}$ & 0 & $2.3 \pm 16.6$ & $2.9 \pm 18.0$ & $6.3 \pm 19.6$ & $7.5 \pm 22.5$ \\
\hline \hline \multirow{2}{*}{$\begin{array}{c}<4 \mathrm{mg} / \mathrm{dL} \\
(\mathrm{n}=86)\end{array}$} & $\begin{array}{c}\mathrm{HDL}-\mathrm{C} \\
(\mathrm{mg} / \mathrm{dL})\end{array}$ & $35.4 \pm 3.2$ & $40.4 \pm 7.6$ & $41.0 \pm 7.5$ & $42.5 \pm 7.8$ & $44.1 \pm 9.3$ \\
\cline { 2 - 7 } & $\begin{array}{c}\% \text { change } \\
\text { from baseline }\end{array}$ & 0 & $14.0 \pm 20.1$ & $16.1 \pm 21.5$ & $20.3 \pm 22.0$ & $24.9 \pm 27.5$ \\
\hline
\end{tabular}

Fig. 3. Effect of pitavastatin on HDL-C. All and baseline HDL-C value is under $40 \mathrm{mg} / \mathrm{dL}$.

Values are the mean $\pm \mathrm{SD}$

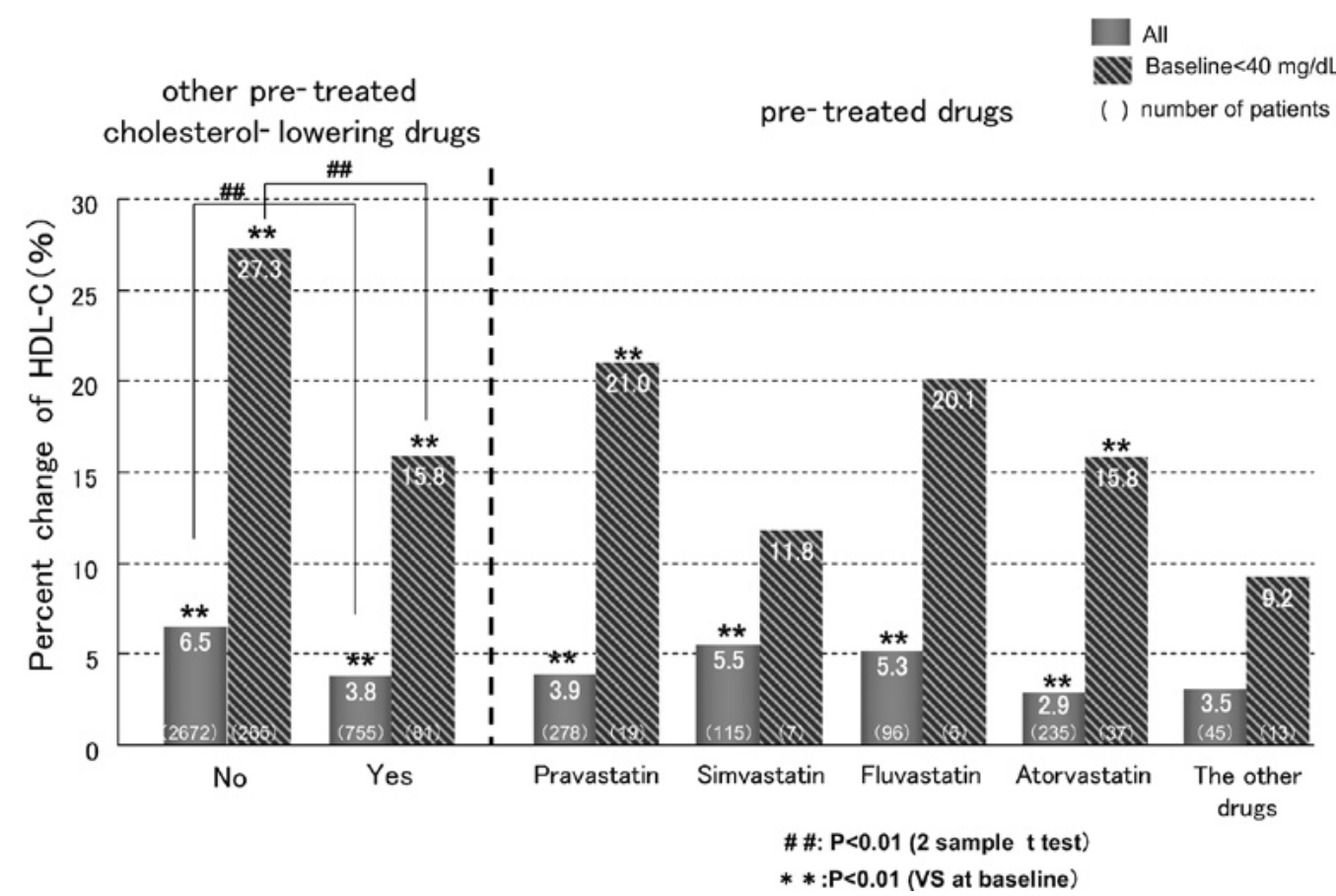

Fig.4. Effect of pitavastatin on HDL-C after switching from other cholesterol-lowering drugs. All and baseline HDL-C values are under $40 \mathrm{mg} / \mathrm{dL}$.

Values are the mean

with statins and other cholesterol-lowering drugs is shown in Fig. 4. Comparing the percent change of
HDL-C in pre-treated patients with naive patients, the latter patients showed a higher percent increase of 
Table 3. Analysis of clinical factors affecting HDL-C

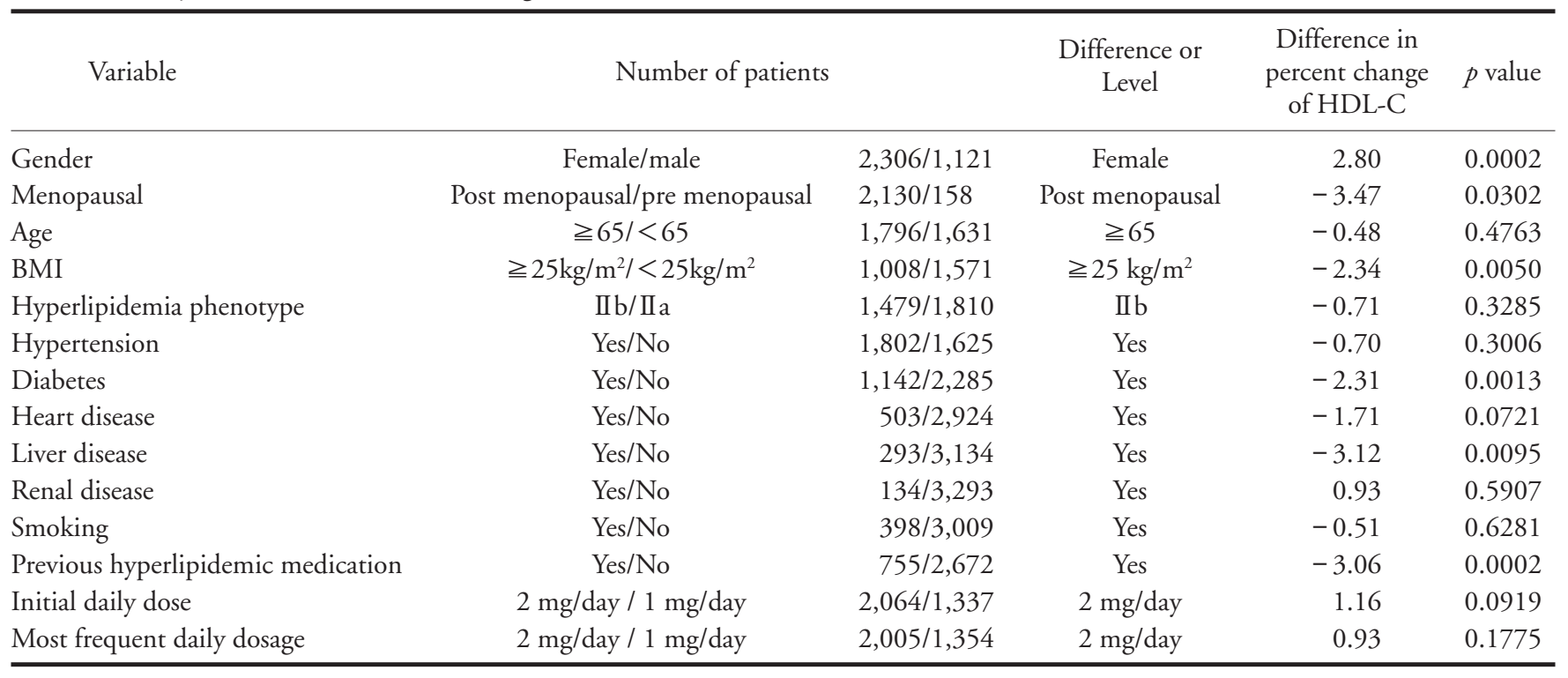

Adjusted HDL-C baseline

Table 4. Analysis of clinical factors affecting HDL-C (Multivariable analysis)

\begin{tabular}{lccc}
\hline \multicolumn{1}{c}{ Variable } & Difference or Level & Estimate & $p$ value \\
\hline Gender & Female & 1.71 & 0.0543 \\
Age & $\geqq 65$ & -0.97 & 0.2305 \\
BMI & $\geqq 25 \mathrm{~kg} / \mathrm{m}^{2}$ & -1.82 & 0.0296 \\
Diabetes & Yes & -2.40 & 0.0046 \\
Liver disease & Yes & -2.89 & 0.0413 \\
Initial daily dose & $2 \mathrm{mg} / \mathrm{day}$ & 1.19 & 0.1439 \\
Previous hyperlipidemic medication & Yes & -3.23 & 0.0009 \\
\hline
\end{tabular}

Adjusted HDL-C baseline

HDL-C than pre-treated patients in both all patients and the low HDL-C group $(p<0.01)$. In the group of pre-treated patients, the percent change of HDL-C was compared among the pretreated drugs. A further increase of HDL-C was observed after switching from other statins.

\section{Analysis of Clinical Factors Affecting HDL-C}

Clinical factors influencing the percent change of HDL-C were investigated (Table 3). In the ANOVA (F-test), gender, menopausal, BMI, diabetes, liver disease, and pre-treated other cholesterol-lowering drug were detected as significant factors affecting the change of HDL-C.

Factors selected by the step-wise method were followed by multivariable analysis. BMI, diabetes, liver disease, and pre-treated other cholesterol-lowering drugs were confirmed as significant factors affecting

\section{HDL-C elevation (Table 4).}

\section{Safety}

Of the 19,925 patients included in the safety evaluation, 2,069 (10.4\%) developed adverse drug reactions. The major adverse drug reactions were blood creatine phosphokinase increased $(2.74 \%)$, alanine aminotransferase (ALT) increased (1.79\%), aspartate aminotransferase (AST) increased (1.50\%), myalgia $(1.08 \%)$ and gamma-glutamyltransferase increased (1.00\%). Most of the adverse drug reactions were mild (mild in 1,735 patients, moderate in 307 patients and serious in 27 patients).

\section{Discussion}

In the current study, pitavastatin showed favorable effects on LDL-C, TG, and HDL-C for 104 
weeks in hypercholesterolemic patients. In particular, it is noted that HDL-C was increased significantly in both all patients and the low HDL-C group after 104 weeks, indicating that pitavastatin is effective for elevation of HDL-C. Barter et al. analyzed Treating to New Targets (TNT) Study data and reported that patients with lower HDL-C levels have a significant higher risk of CAD than patients with higher HDL-C levels even though their LDL-C is controlled under 70 $\mathrm{mg} / \mathrm{dL}^{13)}$. Also, in the BIP trial, it is suggested that HDL-C level-raising therapy is associated with longterm mortality reduction ${ }^{14)}$. Thus, it is suggested that pitavastatin may be beneficial to prevent CVD and reduce mortality due to elevating $\mathrm{HDL}-\mathrm{C}$ in addition to lowering LDL-C.

The lipid values shown in Table 2 were from patients whose data were available at both 0 and 104 weeks, and the time course data were from patients whose data were available all 0, 12, 28, 52 and 104 weeks. Percent changes of LDL-C, TG, and HDL-C were almost the same in Table 2 and the time-course data.

As for analysis of the lipid profile for 104 weeks, it was shown that pitavastatin increased HDL-C continuously until 104 weeks. This increasing trend of HDL-C was also observed in a long-term treatment study of pitavastatin conducted before its launch in clinical use ${ }^{15)}$. In the J-LIT study, an increasing trend was observed by simvastatin for long-term treatment ${ }^{4}$. On the other hand, in long-term treatment studies of other statins, increasing trends of HDL-C were not observed $^{16)}$; therefore, increasing effects on HDL-C might be different among statins in long-term treatment.

In this study, pitavastatin showed a significant effect to increase HDL-C even after switching from other cholesterol-lowering drugs. Consistently, Sasaki et al. reported that pitavastatin elevated HDL-C significantly more than atorvastatin ${ }^{17)}$. The potential mechanisms of raising HDL-C by pitavastatin have been reported. Maejima et al. reported that pitavastatin induced apoA-I more efficiently than simvastatin and atorvastatin, and increased ABCA1 mRNA in a dose-dependent manner in HepG2 cells ${ }^{18)}$. Saiki et al. added that pitavastatin increases the activity of LPL, which metabolizes VLDL and elevates HDL-C, compared with other stains ${ }^{19)}$. It is currently unknown whether these mechanisms are common in statins or are subclass effects that highlight HDL-C elevation by pitavastatin over other statins.

Diabetes was indicated as a significant clinical factor affecting HDL-C elevation. It is well known that diabetes patients have lower levels of HDL-C and a higher risk of CVD than non-diabetes patients ${ }^{20)}$. Recently, it was reported that adiponectin influences the value of HDL-C ${ }^{21)}$. Pitavastatin increases adiponection in hyperlipidemic patients ${ }^{22}$. Since the concentration of adiponectin is lower in diabetes patients than non-diabetes patients ${ }^{23}$, adiponectin could mediate HDL-C elevation in diabeteic patients by pitavastatin.

In this study, we analyzed the efficacy of pitavastatin under actual use conditions using the database of the LIVES study. Since the main purpose of the LIVES study is to generate safety information, in some patients the efficacy data were not available. Therefore, a further prospective long-term clinical trial is needed to evaluate the HDL-C increasing trend of pitavastatin. Also, additional research is required to reveal the mechanisms of HDL-C elevation and its difference between statins.

In conclusion, pitavastain showed potent beneficial effects on LDL-C, TG, and especially HDL-C for 104 weeks, suggesting that pitavastatin may decrease the risk of CVD by maintaining a favorable HDL-C level.

\section{Acknowledgements}

The authors thank all the physicians thorough Japan who participated in the LIVES study, which was supported by Kowa Company Ltd, Tokyo, Japan.

\section{References}

1) William C: Cholesterol and lipids in the risk of coronary artery disease-the Framingham Heart Study. Can J Cardiol, 1988; 4 Suppl A: 5A-10A

2) Assmann G, Schulte H, von Eckardstein A, Huang Y: High-density lipoprotein cholesterol as a predictor of coronary heart disease risk. The PROCAM experience and pathophysiological implications for reverse cholesterol transport. Atherosclerosis, 1996; 124 Suppl: S11-S20

3) Okamura T, Hayakawa T, Kadowaki T, Kita Y, Okayama A, Ueshima H, NIPPON DATA90 Research Group: The inverse relationship between serum high-density lipoprotein cholesterol level and all-cause mortality in a 9.6-year follow-up study in the Japanese general population. Atherosclerosis, 2006; 184: 143-150

4) Matsuzaki M, Kita T, Mabuchi H, Matsuzawa $Y$, Nakaya N, Oikawa S, Saito Y, Sasaki J, Shimamoto K, Itakura H, J LIT Study Group. Japan Lipid Intervention Trial: Large scale cohort study of the relationship between serum cholesterol concentration and coronary events with low-dose simvastatin therapy in Japanese patients with hypercholesterolemia. Primary prevention cohort study of the Japan lipid intervention trial (J-LIT). Circ J, 2002; 66: $1087-$ 1095

5) Downs JR, Clearfield M, Weis S, Whitney E, Shapiro 
DR, Beere PA, Langendorfer A, Stein EA, Kruyer W, Gotto AM Jr: Primary prevention of acute coronary events with lovastatin in men and women with average cholesterol levels: results of AFCAPS/TexCAPS. Air Force/ Texas Coronary Atherosclerosis JAMA, 1998; 279: 16151622

6) Scandinavian Simvastatin Survival Study Group. Randomised trial of cholesterol lowering in 4444 patients with coronary heart disease: the Scandinavian Simvastatin Survival Study (4S). Lancet, 1994; 344: 1383-1389

7) Sacks FM, Pfeffer MA, Moye LA, Rouleau JL, Rutherford JD, Cole TG, Brown L, Warnica JW, Arnold JM, Wun CC, Davis BR, Braunwald E: The effect of pravastatin on coronary events after myocardial infarction in patients with average cholesterol levels. N Engl J Med, 1996; 335: 1001-1009

8) The Long-Term Intervention with Pravastatin in Ischaemic Disease (LIPID) Study Group. Prevention of cardiovascular events and death with pravastatin in patients with coronary heart disease and a broad range of initial cholesterol levels. N Engl J Med, 1998; 339: 1349-1357

9) Suzuki H, Aoki T, Tamaki, Sato F, Kitahara M, Saito Y: Hypolipidemic effect of NK-104, a potent HMG-CoA reductase inhibitor, in gunea pigs. Atherosclerosis, 1999; 146: 259-270

10) Saito $Y$, Yamada N, Teramoto T, Itakura H, Hata $Y$, Nakaya N, Mabuchi H, Tushima M, Sasaki J, Ogawa N, Goto Y: A randomized, double-blind trial comparing the efficacy and safety of pitavastatin versus pravastatin in patients with primary hypercholesterolemia. Atherosclerosis, 2002; 162: 373-379

11) Kurihara Y, Douzono T, Kawakita K, Nagasaka Y: A largescale, long-term, prospective post-marketing surveillance of pitavastatin (LIVALO Tablet)-LIVALO effectiveness and safety (LIVES) study-. Jpn Pharmacol Ther, 2008; 36: 709-731

12) Freidewald WT, Levy RI, Fredrikson DS: Estimation of the concentration of low-density cholesterol in plasma, without the use of the preparative ultracentrifuge. Clin Chem, 1972; 18: 499-502

13) Barter P, Gotto AM, LaRosa JC, Maroni J, Szarek M, Grundy SM, Kastelein JJ, Bittner V, Fruchart JC, Treating to New Targets Investigators: HDL cholesterol, very low levels of LDL cholesterol, and cardiovascular events. N Engl J Med, 2007; 357: 1301-1310

14) Goldenberg I, Boyko V, Tennenbaum A, Tanne D, Behar S, Guetta V: Long-term benefit of high-density lipoprotein cholesterol-raising therapy with bezafibrate:16-year mortality follow-up of the bezafibrate infarction prevention trial. Arch Intern Med, 2009; 169: 508-514

15) Teramoto T, Saito Y, Nakaya: Clinical evaluation of NK-104 (itavastatin) in ling-term treatment of patients with hyperlipidemia. Atherosclerosis, 2000; 151: 353 Abstract

16) Olsson AG, Istad H, Luurila O, Ose L, Stender S, Tuomilehto J, Wiklund O, Southworth H, Pears J, Wilpshaar JW, Rosuvastatin Investigators Group: Effects of rosuvastatin and atorvastatin compared over 52 weeks of treatment in patients with hypercholesterolemia. Am Heart J, 2002; 144: 1044-1051

17) Sasaki J, Ikeda Y, Kuribayashi T, Kajiwara K, Biro S, Yamamoto K, Ageta M, Kobori S, Saikawa T, Otonari T, Kono S: A 52-week, randomized, open-label, parallelgroup comparison of the tolerability and effects of pitavastatin and atorvastatin on high-density lipoprotein cholesterol levels and glucose metabolism in Japanese patients with elevated levels of low-density lipoprotein cholesterol and glucose intolerance. Clin Ther, 2008; 30: 1089-1101

18) Maejima T, Yamazaki H, Aoki T, Tamaki T, Sato F, Kitahara M, Saito Y: Effect of pitavastatin on apolipoprotein A-I production in HepG2 cell. Biochem Biophys Res Commun, 2004; 324: 835-839

19) Saiki A, Murano T, Watanabe F, Oyama T, Miyashita Y, Shirai K: Pitavastatin enhanced lipoprotein lipase expression in 3T3-L1 preadiocytes. J Atheroscler Thromb, 2005; 12: $163-168$

20) Oikawa S, Kita T, Mabuchi H, Matsuzaki M, Matsuzawa Y, Nakaya N, Saito Y, Sasaki J, Shimamoto K, Itakura H, J-LIT Study Group: Risk of coronary events in Japanese patients with both hypercholesterolemia and type 2 diabetes mellitus on low-dose simvastatin therapy: implication from Japan Lipid Intervention Trial (J-LIT). Atherosclerosis, 2007; 191: 440-446

21) Zoccali C, Mallamaci F, Tripepi G, Benedetto FA, Cutrupi S, Parlongo S, Malatino LS, Bonanno G, Seminara G, Rapisarda F, Fatuzzo P, Buemi M, Nicocia G, Tanaka S, Ouchi N, Kihara S, Funahashi T, Matsuzawa Y: Adiponectin, metabolic risk factors, and cardiovascular events among patients with end-stage renal disease. J Am Soc Nephrol, 2002; 13: 134-141

22) Inami $N$, Nomura $S$, Shouzu A, Omoto S, Kimura $Y$, Takahashi N, Tanaka A, Nanba M, Shouda Y, Iwasaka T: Effects of pitavastatin on adiponectin in patients with hyperlipidemia. Pathophysiol Haemost Thromb, 2007; 36: $1-8$

23) Hotta K, Funahashi T, Arita Y, Takahashi M, Matsuda M, Okamoto Y, Iwahashi H, Kuriyama H, Ouchi N, Maeda K, Nishida M, Kihara S, Sakai N, Nakajima T, Hasegawa K, Muraguchi M, Ohmoto Y, Nakamura T, Yamashita S, Hanafusa T, Matsuzawa Y: Plasma concentrations of a novel, adipose-specific protein, adiponectin, in type 2 diabetes patients. Artherioscler Thromb Vasc Biol, 2000; 20: 1595-1599 